\title{
Contribuição da Oficina Profissional do Profnit para a Secretaria de Inovação da UFSC
}

\author{
Contributions of Profnit's Practical Training Course to Technological \\ Innovation Center of the Federal University of Santa Catarina
}

\author{
Breno Ricardo de Araújo Leite ${ }^{1}$ \\ Paulo Roberto Lisboa Arruda ${ }^{1}$ \\ Danielle Regina da Natividade Ferreira ${ }^{1}$ \\ Thiago Domingos Marques ${ }^{1}$ \\ Alexandre Moraes Ramos ${ }^{1}$ \\ Irineu Afonso Frey ${ }^{1}$ \\ ${ }^{1}$ Universidade Federal de Santa Catarina, Florianópolis, SC, Brasil
}

\begin{abstract}
Resumo
A Oficina Profissional é uma disciplina obrigatória do Programa de Pós-Graduação Profnit e, no caso da UFSC, constitui-se como um estágio de 180 horas que tem como intuito capacitar e contribuir na formação dos alunos em atividades práticas, executando tarefas específicas em instituições parceiras do Ponto Focal do programa. Em 2019 ocorreram quatro oficinas que trouxeram relevantes contribuições para a Secretaria de Inovação da UFSC, o que motivou a realização deste trabalho para relatar os casos ocorridos, com os seguintes temas: mapeamento de patentes, portfólio de tecnologias, cultivares, indicação geográfica, Política de Inovação e Política de Confidencialidade. Os procedimentos metodológicos utilizados foram prospecção tecnológica, levantamento, pesquisa bibliográfica $e$ documental. Os principais resultados foram mapeamento das patentes, estruturação do portfólio de tecnologias, proposta de política de confidencialidade e de inovação, mapeamento das indicações geográficas e cultivares da UFSC. Acredita-se que o relato dessa experiência de sucesso pode servir de referência para outros pontos focais do Profnit, além de inspiração para que iniciativas como essa sejam implementadas e replicadas nas políticas públicas envolvendo mestrados profissionais no Brasil.
\end{abstract}

Palavras-chave: Portfólio de Tecnologias. Política de Inovação. Política de Confidencialidade.

\begin{abstract}
The practical training course of the postgraduate program Profnit consists of a stage of 180 hours, which aims to empower students in practical activities, performing specific tasks in the partnerships focal point institutions. Four stages brought relevant contributions to the Technological Innovation Center of Federal University of Santa Catarina in 2019. These motivated the realization of this work addressed to report four cases related to the following topics: patent mapping, technology portfolio, plant breeders' rights, geographic indication, Innovation Policy, and Confidentiality Policy. The methodological procedures used were technological forecasting, survey, bibliographic and documentary research. The main results were patent mapping, technology portfolio, the proposal of confidentiality and innovation policy, mapping of geographic indications, and plant breeders' rights. We believe that the report of this experience of success can serve as a reference for other focal points of Profnit, besides being an inspiration for initiatives such as this to be implemented and replicated in public policies involving professional master's degrees in Brazil
\end{abstract}

Keywords: Portfolio of Technologies. Innovation Policy. Confidentiality Policy.

Área Tecnológica: Propriedade Intelectual. Gestão da Inovação. 


\section{Introdução}

O Programa de Pós-Graduação em Propriedade Intelectual e Transferência de Tecnologia para a Inovação (PROFNIT ${ }^{\circledR}$ ) consiste de um Mestrado Profissional em Rede Nacional, coordenado pela Associação Fórum Nacional de Gestores de Inovação e Transferência de Tecnologia (FORTEC) e integrado por Pontos Focais e Instituições Associadas (PROFNIT, 2018).

O Profnit oferta anualmente um curso presencial, na modalidade de Mestrado Profissional,

[...] destinado à formação de agentes multiplicadores e pesquisadores na área de Propriedade Intelectual, Transferência de Tecnologia e Inovação Tecnológica, de forma relevante e articulada com a atuação de Núcleos de Inovação Tecnológica (NIT) das organizações. (PROFNIT, 2018, p. 1)

O Programa visa ao "[...] aprimoramento da formação profissional para atuar nas competências dos NITs e nos Ambientes Promotores de Inovação nos diversos setores acadêmico, empresarial, governamental, organizações sociais, etc." (PROFNIT, 2019a, p.1).

A Universidade Federal de Santa Catarina (UFSC) integra o rol de pontos focais do Profnit desde o primeiro Exame Nacional de Acesso em 2016 (PROFNIT, 2016), tendo estabelecido parceria com instituições localizadas no estado catarinense para oferecer ao seu corpo discente as condições ideais para seu aprimoramento profissional, como a cooperação com a Secretaria de Inovação (SINOVA) da UFSC (SINOVA, 2019).

A Sinova está constituída como NIT da UFSC, sendo responsável pela proteção da propriedade intelectual, promoção da cultura de inovação, pela coordenação da transferência de tecnologia e da política de inovação, entre outras atividades comuns dos NITs (BRASIL, 2004). No caso específico do Profnit, a contribuição da Sinova se dá por meio da oferta de vagas para a disciplina de Oficina Profissional do programa de mestrado.

A Oficina Profissional é uma das disciplinas obrigatórias do Profnit e, no caso da UFSC, constitui-se de um estágio de 180 horas, que tem como intuito capacitar e contribuir na formação dos alunos em atividades práticas, em uma das instituições parceiras do ponto focal, executando tarefas específicas e com objetivo definido, como: estudos de prospecção tecnológica e de inteligência competitiva no campo da propriedade intelectual, legislação e políticas públicas referentes à propriedade intelectual e transferência de tecnologia para inovação tecnológica, promoção e acompanhamento de relacionamento academia-empresa, políticas de estímulo à proteção das criações, entre outros (PROFNIT, 2019b).

Tendo em vista a relevante contribuição da Oficina Profissional do Profnit para a Sinova em 2019, o presente trabalho aborda o relato de quatro casos ocorridos no primeiro semestre de 2019, dando enfoque ao diferencial trazido pelos alunos e destacando o ganho bilateral dessa parceria de sucesso entre a Sinova e o Profnit-UFSC.

Acredita-se que os relatos dessa experiência de sucesso podem servir de referência para outros pontos focais do Profnit, de forma a unir o estágio prático da pós-graduação com a geração de resultados e de produtos de impacto imediato em cada NIT associado aos pontos focais, além de inspiração para que iniciativas como essa sejam implementadas e replicadas nas políticas públicas envolvendo mestrados profissionais no Brasil. 


\section{Metodologia}

A metodologia utilizada no estudo foi a descritiva, que tem como propósito relatar o que foi desenvolvido nas quatro oficinas profissionais realizadas por quatro alunos do Profnit-UFSC, no primeiro semestre de 2019. Considerando que cada caso foi construído para atender aos objetivos específicos e diferentes entre si, os casos são tratados neste artigo de forma separada por subtítulos em cada seção que abrange os seguintes temas e processos metodológicos: mapeamento de patentes (prospecção tecnológica) e portfólio de tecnologias (pesquisa documental e levantamento), práticas de sigilo e confidencialidade nos processos de inovação aberta (pesquisa documental e levantamento), cultivares e indicação geográfica (pesquisa bibliográfica $e$ documental) e política de inovação (pesquisa documental e levantamento).

\subsection{Mapeamento de Patentes e Portfólio de Tecnologias}

As atividades desta Oficina Profissional foram realizadas para atender a dois objetivos específicos, cada um deles subdividido em fases.

Objetivo 1: Mapear as Patentes da UFSC - este mapeamento foi realizado para verificar se todas as patentes que citam a UFSC como titular ou cotitular constavam na planilha de controle da Sinova, subdividido em duas fases, referentes às patentes nacionais e internacionais.

Fase 1: Levantar patentes nacionais da UFSC - foi realizado um amplo levantamento na base de dados de patentes do Instituto Nacional da Propriedade Industrial (INPI, 2019) para verificar se todas as patentes depositadas pela UFSC, ou em cotitularidade com outras instituições, constavam na planilha de controle da Sinova. Foram testadas várias estratégias de busca, incluindo código CNPJ e diversos operadores de truncamento, visto que haviam várias grafias diferentes para o nome do titular: UFSC.

Fase 2: Levantar patentes internacionais da UFSC - com o mesmo objetivo anterior, foi realizado um levantamento na base de dados de patentes do Derwent Innovations Index (DII) (DII, 2019) para localizar as patentes da UFSC depositadas em outros países, pois, na planilha de controle, apenas as patentes nacionais eram acompanhadas, visto que, normalmente, a UFSC não se responsabiliza por depósitos internacionais, ficando esse encargo para o cotitular da patente, caso haja. Esses resultados foram confrontados com as patentes buscadas em outra base de dados, do software Orbit Intelligence (ORBIT QUESTEL, 2019), cujo acesso foi possível devido à parceria do Profnit com a empresa Axonal Consultoria Tecnológica.

Objetivo 2: Estruturar o Portfólio de Tecnologias - o Portfólio de Tecnologias da UFSC foi proposto com o intuito de agregar mais informações, além daquelas já disponíveis no conteúdo das patentes, de forma a oferecer dados mais precisos e inteligíveis para o profissional responsável pela negociação dessas patentes e, com isso, favorecer as transferências dessas tecnologias para a iniciativa privada, o que poderá transformar as invenções em inovações, além de gerar royalties para a UFSC. Como não havia tempo hábil para realizar esse estudo para todas as patentes da UFSC, apenas as patentes vigentes, que não estavam no período de sigilo e que não dispunham de cotitulares, foram selecionadas para o estudo. Este objetivo foi subdividido em três fases.

Fase 1: Inserir dados gerais das patentes - a partir da base de dados de patentes do INPI, as patentes selecionadas foram analisadas, individualmente, para identificar alguns dados impor- 
tantes, como área de pesquisa, aplicação industrial e vantagens competitivas frente ao estado da técnica (INPI, 2019). O Orbit Intelligence também foi utilizado para classificar as patentes com base nos domínios tecnológicos da Questel (ORBIT QUESTEL, 2019), criados a partir das classes e das subclasses da Classificação Internacional de Patentes. Esses dados servirão de subsídio para auxiliar na negociação futura dessas patentes com o setor privado.

Fase 2: Identificar potenciais parceiros - foram localizadas algumas empresas de médio e grande porte, situadas preferencialmente no Estado de Santa Catarina ou na Região Sul, que pudessem ser eventuais interessadas em uma cessão ou no licenciamento das patentes selecionadas, de acordo com a aplicação industrial das patentes e o ramo de atuação das empresas. Os dados foram coletados a partir do Observatório da Indústria Catarinense da Federação das Indústrias do Estado de Santa Catarina (FIESC), que é uma área voltada ao planejamento e desenvolvimento estratégico da indústria do Estado (FIESC, 2019), além de uma busca no próprio site de cada empresa na internet. Com base nesses dados, a Sinova saberá para quais empresas poderá oferecer a tecnologia, de forma a aumentar a chance de sucesso.

Fase 3: Calcular a maturidade das patentes - para identificar o nível de maturidade ou de prontidão das patentes, foi utilizada uma calculadora, obtida a partir do New York State Energy Research and Development Authority (NYSERDA, 2019). Essa calculadora foi selecionada por ser de preenchimento mais simples e conter também aspectos relacionados com a comercialização, pois integra tanto o Technology Readiness Level (TRL) quanto o Commercialization Readiness Level (CRL). Os dados foram coletados a partir de um questionário disponibilizado via internet para os pesquisadores, utilizando uma plataforma gratuita de "Survey". Essa etapa não foi $100 \%$ cumprida pelo fato de alguns pesquisadores não terem respondido ao questionário. Essa informação será muito útil para assessorar as empresas contatadas no momento de definir quanto de desenvolvimento ainda será necessário para transformar a tecnologia licenciada em produto de mercado.

\subsection{Práticas de Sigilo e Confidencialidade nos Processos de Inovação Aberta}

O trabalho foi desenvolvido com base em três objetivos.

Objetivo 1: Buscar o arcabouço jurídico e benchmarking - pesquisa documental de todo o arcabouço jurídico que se relaciona com o tema e verifica documentos jurídicos de outras instituições.

Fase 1: Estudar o arcabouço jurídico a respeito do tema - a atividade proposta foi a pesquisa documental de todo o arcabouço jurídico que se relaciona com o tema. Após vasta pesquisa, identificou-se que 18 legislações guardavam relação com sigilo e confidencialidade, o incentivo à pesquisa e à inovação, as responsabilizações em geral e com as formas de acesso à informação.

Fase 2: Realizar benchmarking dos termos de confidencialidade em outras instituições - o benchmarking realizado estava vinculado às políticas e aos termos de confidencialidade existentes nos NITs de outras instituições, conforme mostra a sugestão fornecida pela Sinova (Embrapa, UFSCAR, UFMG, UFPR, UFTPR, UFRGS, UFRJ, UNB, Unicamp, USP). O referido estudo esteve pautado no encaminhamento de e-mail para as instituições listadas solicitando informações sobre possuírem política de confidencialidade já organizada e os termos (NDA) 
utilizados, além de pesquisa nos sítios dos departamentos de inovação das instituições que não responderam ao e-mail.

Fase 3: Elaborar a Política de Confidencialidade para a UFSC - trata-se de um guia que auxilia as partes interessadas (instituições de ensino, funcionários, pesquisadores, parceiros, etc.) a compreender as formas de execução e de proteção das tratativas realizadas entre pesquisador e parceiro.

Objetivo 2: Revisar os Instrumentos Jurídicos da Sinova - revisão de todos os documentos jurídicos da Sinova para adequá-los à legislação vigente.

Fase 1: Revisar as cláusulas dos modelos de minuta do Tramita Fácil - foi necessário identificar quais os documentos em que seria necessário algum tipo de análise, tendo sido identificados 27 tipos, divididos em cinco temas principais, porém, a análise dos documentos ficou comprometida, tendo em vista que eles não estavam disponíveis para acesso pelo sistema Tramita Fácil. Após contato telefônico com a Coordenadoria de Projetos para obter informações sobre o Tramita Fácil, recebeu-se a informação de que os documentos estariam localizados em http://dpc.proad.ufsc.br.

Fase 2: Revisar os documentos técnicos de recomendações de Non-Disclosure Agreement (NDA) - foi realizada a ampla análise e revisão dos 10 documentos existentes, com as sugestões de ajustes pertinentes.

Fase 3: Elaborar os formulários de NDA (servidores, reuniões, projeto) - foram recebidos 14 documentos, sendo que apenas três eram de fato necessários ao prosseguimento do trabalho. Foram realizadas a ampla análise e a revisão dos documentos citados, com as sugestões de ajustes pertinentes.

Objetivo 3: Elaborar Cartilha de boas práticas com perguntas frequentes para comunidade acadêmica - a elaboração da cartilha foi pautada em documento a ser utilizado entre pessoas que não possuem qualquer domínio sobre os temas de sigilo e confidencialidade, portanto, o seu texto foi bastante direto e informal.

\subsection{Cultivares e Indicação Geográfica}

As atividades realizadas nesta Oficina Profissional foram divididas para atender a três Objetivos Específicos.

Objetivo 1: Mapear os cultivares - levantar todos os cultivares relacionados à UFSC para viabilizar o controle pela Sinova. Realizar consulta ao sítio eletrônico CultivarWeb do Ministério da Agricultura, Pecuária e Abastecimento (MAPA) na internet (CULTIVARWEB, 2019) para verificar todas as cultivares registradas e protegidas que tenham a UFSC como titular ou cotitular.

Objetivo 2: Mapear as indicações geográficas catarinenses - levantar as indicações geográficas catarinenses e as potencialidades de projetos futuros de indicação geográfica para conhecimento da Sinova e gestão de futuras parcerias. Após, realizada uma pesquisa no sítio eletrônico do INPI (2019) sobre os processos de indicações geográficas catarinenses, Indicações de Procedência (IP) e Denominações de Origem (DO) registradas e em andamento, foram identificadas as potencialidades de alguns produtos/projetos desenvolvidos em Santa Catarina com os quais a UFSC colabora ou poderá colaborar no desenvolvimento do registro da Indicação Geográfica em parceria com outros órgãos, com base no banco de dados da Empresa de 
Pesquisa Agropecuária e Extensão Rural de Santa Catarina (EPAGRI) e do Serviço Brasileiro de Apoio às Micro e Pequenas Empresas (SEBRAE).

Objetivo 3: Preparar material de divulgação para a Sinova - preparar folders sobre Proteção de Cultivares, Indicação Geográfica (IG) e Registro Nacional de Cultivar (RNC). Após consulta à legislação e pesquisa de artigos científicos relacionados aos temas, foram elaborados três folders informativos sobre RNC, proteção de cultivares e indicação geográfica.

\subsection{Política de Inovação}

Esta Oficina Profissional foi realizada com o objetivo de propor uma minuta de Política de Inovação para a UFSC, conforme previsto pelo artigo 15-A da Lei da Inovação (BRASIL, 2004), e foi dividida em três fases:

Fase 1: Estudar o arcabouço jurídico a respeito do tema - a atividade proposta foi o desenvolvimento de estudo sobre a legislação que trata de Política de Inovação, com a finalidade de atender à legislação prevista, dar segurança jurídica para os gestores públicos e auxiliar nas definições de competências. Os resultados foram tabulados para referência futura e utilizados para estruturar a minuta.

Fase 2: Realizar levantamento das Políticas de Inovação de outras instituições de ensino e pesquisa - foram consultadas por telefone, mensagem eletrônica e acesso em seus respectivos sítios eletrônicos as seguintes instituições: UFMG, UFRGS, UFRJ, USP, Unicamp, Fiocruz e Embrapa. Verificou-se que todas dispunham de políticas de inovação bem estruturadas que foram utilizadas como benchmarking para o trabalho que seria iniciado na fase seguinte, considerando os pontos fortes de cada uma das políticas levantadas.

Fase 3: Elaborar e apresentar a proposta de Política de Inovação - considerando todo o material que havia sido consultado, uma primeira minuta de Política de Inovação para a UFSC foi proposta. Essa minuta foi apresentada ao efetivo da Sinova em três oportunidades ao longo da Oficina para debates, sugestões, complementações, readequações e validação. Este trabalho resultou em uma versão final, que foi submetida à avaliação do procurador do órgão de controle da União responsável por assessorar a UFSC nos aspectos jurídicos de sua atuação.

\section{Resultados e Discussão}

Os resultados dessas oficinas serão apresentados a seguir de forma bastante consolidada e objetiva, sem descriminar, novamente, as fases e os objetivos de cada caso.

\subsection{Mapeamento de Patentes e Portfólio de Tecnologias}

O mapeamento de patentes feito a partir da base de dados de patentes do INPI permitiu que 10 patentes, que não constavam na planilha de controle da Sinova, pudessem ser localizadas e inseridas devidamente na referida planilha. Essa diferença se deu, principalmente, pelo fato de ter diferentes grafias do nome do Titular, inclusive com erros de grafia, como: UFSC, Universidade Federal de Santa Catarina, Univ. Federal de Santa Catarina, Universidade Federal Santa Catarina, Univerdidade Federal de Santa Catarina; e Universidade Ferderal de Santa Catarina. 
A busca na base do DII recuperou 37 patentes que foram inseridas na planilha de controle. O software Orbit Intelligence foi utilizado para reforçar as duas buscas anteriores, mas não foram encontradas novas patentes que já não tivessem sido localizadas no INPI e DII.

O Portfólio de Tecnologias da UFSC foi proposto com o intuito de agregar mais informações, com dados mais precisos e úteis para auxiliar o profissional responsável pela negociação dessas patentes, tendo gerado os seguintes dados adicionais: área de pesquisa, domínio tecnológico, aplicação industrial, vantagens competitivas frente ao estado da técnica, eventuais empresas interessadas em transferência de tecnologia e nível de maturidade das patentes selecionadas. Todas essas informações estão tabuladas em uma planilha eletrônica que foi disponibilizada para a Sinova. Um exemplo de dados tabulados no Portfólio de Tecnologias pode ser verificado na Tabela 1.

Tabela 1 - Exemplo de dados tabulados na Planilha com o Portfólio de Tecnologias da UFSC

\begin{tabular}{|c|c|c|c|c|c|c|}
\hline NúMERo & $\begin{array}{l}\text { ÁREA dE } \\
\text { PESQuisa }\end{array}$ & $\begin{array}{l}\text { Domínio } \\
\text { TECNOLÓ- } \\
\text { gico }\end{array}$ & $\begin{array}{l}\text { APLICAÇÃo } \\
\text { INDUSTRIAL }\end{array}$ & $\begin{array}{c}\text { VANTAGENS COMPETI- } \\
\text { TIVAS }\end{array}$ & $\begin{array}{l}\text { Eventuais } \\
\text { ParceIRos }\end{array}$ & TRL/CRL \\
\hline EP3382737 & $\begin{array}{c}\text { Engenharia } \\
\text { Química }\end{array}$ & $\begin{array}{l}\text { Tratamento } \\
\text { de superfície } \\
\text { revestimento }\end{array}$ & $\begin{array}{l}\text { Tratamento } \\
\text { de superfícies } \\
\text { com plasma }\end{array}$ & $\begin{array}{l}\text { Método mais eficiente } \\
\text { para evitar condensação } \\
\text { de impurezas no interior } \\
\text { da câmara de tratamento }\end{array}$ & $\begin{array}{c}\text { Villares } \\
\text { Lupatech } \\
\text { Plasmatech }\end{array}$ & $7 / 5$ \\
\hline
\end{tabular}

Fonte: Elaborada pelos autores deste artigo (2019)

\subsection{Práticas de Sigilo e Confidencialidade nos Processos de Inovação Aberta}

A pesquisa identificou 18 legislações que guardavam alguma relação com sigilo e confidencialidade, o incentivo à pesquisa e à inovação, as responsabilizações em geral $e$ as formas de acesso à informação. Para facilitar a replicação deste trabalho futuramente por outras instituições, destacou-se os artigos de cada uma delas que pudessem corroborar com o desenvolvimento do trabalho (Tabela 2) e com o assunto pertinente.

Tabela 2 - Legislações consultadas e seus respectivos artigos que corroboraram com o desenvolvimento do trabalho

\begin{tabular}{|c|c|c|}
\hline Legislação & Assunto & Artigos \\
\hline Código Civil & Negócios jurídicos & art. 186,187 e 188 \\
\hline Lei n. 8.159/1991 & Proteção de arquivos públicos e privados & art. $4^{\circ}, 6^{\circ}$ e 25 \\
\hline Lei n. 9.279/1996 & $\begin{array}{l}\text { Direitos e obrigações relativos } \\
\text { a propriedade industrial }\end{array}$ & $\begin{array}{l}\text { art. } 6^{\circ} \text { caput, } \S 4^{\circ}, \text { art. } 12 \text { caput, parágrafo } \\
\text { único; artigo } 16 \S 2^{\circ} \text {, art. } 30 \text {, art. } 75 \\
\text { caput, } \$ 1^{\circ}, \text { art. } 88 \text { caput, } \S 2^{\circ}, \text { art. } 90 \\
\text { caput, art. } 105 \text { caput, art. } 106, \S 1^{\circ}, \\
\text { art. } 139 \text { caput, art. } 195 \mathrm{XI}, \text { art. } 204 \\
\text { caput, art. } 206 \text { caput, art. } 231 \text { caput }\end{array}$ \\
\hline Decreto n. 2.553/98 & $\begin{array}{l}\text { Direitos e obrigações relativos } \\
\text { a propriedade industrial }\end{array}$ & $\begin{array}{l}\text { art. } 1^{\circ} \text { caput, } \S 1^{\circ} \text {, art. } 2^{\circ} \\
\text { parágrafo único, art. } 5^{\circ}\end{array}$ \\
\hline Lei n. 9.456/1997 & Proteção de cultivares & art. $2^{\circ}$ caput, art. 13 \\
\hline
\end{tabular}


Legislação

Lei n. 9.610/1998

Lei n. 10.973/2004

Decreto $n$. 9.283/2018

Lei n. 11.105/2005

Lei n. 12.527/2011

Decreto n. $7.845 / 2012$

Lei n. 12.846/2013

Lei n. 13.123/2015

Decreto $\mathrm{n}$.

8.772/2016
Assunto

Proteção da propriedade intelectual no direito autoral

Incentivos à inovação, pesquisa científica e tecnológica

Incentivos à inovação, pesquisa científica e tecnologia

Segurança sobre organismos geneticamente modificados

Acesso à informação

Classificação do grau de sigilo das informações

Responsabilização administrativa e civil

Sobre proteção do patrimônio genético

Sobre proteção do patrimônio genético

\section{Artigos}

art. $1^{\circ} \mathrm{X}$, art. 10 , art. 16 caput $\S 3^{\circ}$, art. $29 \mathrm{VI}$, art. 44, art. $49 \mathrm{~V}, \mathrm{VI}$, art. 52, art. 53 caput, art. 54 caput, art.102, art. 108

art. $1^{\circ}$ Parágrafo único: I, II, V, art. $6^{\circ} \$ 6^{\circ}$, art. $9^{\circ}$-A, art. 11 , art. 26

art. $10 \S 4^{\circ}$, art. $17 \S 4^{\circ}$, art. $2 \S 4^{\circ}$ III $\S 8^{\circ}$ I, art. 44 IV, art. $51 \S 3^{\circ}$ e $4^{\circ}$, art. 54 , art. 67 $\S 4^{\circ}$, art. 68 , art. $69 \S 3^{\circ}$ e $4^{\circ}$, art. $186-\mathrm{E} \S 4^{\circ}$

art. $2^{\circ} \S 1^{\circ}$, art. $14 \mathrm{XIX}$, art. 20 , art. 21 , art. 23

art. $4^{\circ}$ III, art. $6^{\circ}$ III, art. $7^{\circ} \S 1^{\circ}, \S 2^{\circ}$, art. $11 \S 4^{\circ}$, art. 16 I, II, III, art. 25, art. 32 IV

art. 18 , art. 48 , Anexo I

$\operatorname{art.} 2^{\circ}$, art. $3^{\circ} \S 2^{\circ}$, art. $5^{\circ}$, art. 11 , art. $16 \S 1^{\circ} \mathrm{I}$

art. $9^{\circ}$, art. $11 \S 2^{\circ}$, art. $25 \S 2^{\circ}$, art. $38 \S 1^{\circ}$,

$\S 2^{\circ}$, art. 39 caput, art. 40 , art. $41 \S 6^{\circ}$

art. $5^{\circ} \S 6^{\circ}$, art. $25 \S 2^{\circ}$, art. $57 \S 1^{\circ}$, $\S 2^{\circ}$, art. $104 \S 1^{\circ}, \S 2^{\circ}, \S 6^{\circ}$

Fonte: Elaborada pelos autores deste artigo (2019)

As seguintes legislações também foram consultadas, mas não foram identificados dispositivos que pudessem contribuir com o trabalho: Constituição Federal de 1988; Decreto n. 1.171/94, que aprova o Código de Ética Profissional do Servidor Público Civil do Poder Executivo Federal; Lei n. 9.609/1998, proteção da propriedade intelectual de programa de computador; $e$ Lei n. 12.965/2014, proteção de dados pessoais, princípios, garantias, direitos e deveres para o uso da Internet.

De 10 instituições contatadas por e-mail para responder à situação da política de confidencialidade, apenas retornaram as seguintes: UFMG, UFPR, UFTPR E UFSCAR, sendo que tais instituições não possuem a descrição de sua política de confidencialidade, mas apenas os modelos de NDA que utilizam. Passou-se então para a pesquisa nos sítios dos departamentos de inovação das instituições que não responderam (Embrapa, UFRGS, UFRJ, UNB, Unicamp, USP). Identificou-se que tais instituições não possuem disponibilizado em seu sítio uma política de confidencialidade já formulada e que quatro delas não possuem termo de confidencialidade disponível para acesso (UFRGS, UNB, USP, UFRJ). Verificou-se a inexistência de política de confidencialidade em todas as instituições consultadas, mas apenas foram obtidos os termos de confidencialidade em oito delas.

A Política de Confidencialidade da UFSC foi construída pautando os aspectos importantes para a construção de uma negociação que envolva um termo de confidencialidade. A Política de Confidencialidade foi dividida em oito capítulos: Objetivos, Definições, Do acesso à informação, Da estruturação do termo de confidencialidade, Do descarte e preservação dos documentos, Da ação ou omissão, Dos crimes e Das Disposições Gerais, além de 28 artigos ao todo.

Para a revisão das cláusulas dos modelos de minuta do Tramita Fácil, foram identificados cinco documentos que guardam relação com contratos de confidencialidade: Termo de 
Convênio Tripartite; Convênio; Acordo de Cooperação Técnica; Acordo de Cooperação entre Universidades; e Protocolo de intenções, tendo sido realizadas as respectivas sugestões para modificação das cláusulas existentes.

Para a revisão dos documentos técnicos de recomendações de NDA, foi realizada a análise dos 10 documentos existentes. Tendo em vista a relação dessas análises com os NDAs revisados, foi sugerida a manutenção dos NDAs, mantendo como recomendação o Foro de Florianópolis para dirimir eventuais controvérsias. As devidas sugestões de alteração foram apresentadas nos seguintes documentos: NDA Modelo - referente aos projetos e P\&D; NDA de reunião utilizado em reuniões da Sinova (modelo breve); NDA Colaboradores - usado para servidores e bolsistas da Sinova.

A elaboração da cartilha de boas práticas e de material para divulgação à comunidade acadêmica sobre os itens sigilo e confidencialidade foi pautada em documento a ser utilizado entre pessoas que não possuem qualquer domínio sobre os temas de sigilo e confidencialidade. Dessa forma, buscou-se a criação de algo objetivo e de fácil manuseio justamente para tornar a leitura agradável, mas esclarecedora ao ponto que não surjam dúvidas sobre o tema. Assim, a intenção foi criar um documento didático e bem simples. A cartilha é composta de 24 perguntas e respostas sobre os termos de confidencialidade - NDA.

Este trabalho foi muito importante, pois auxiliará os envolvidos na construção de mecanismos de proteção, tanto do próprio documento a ser assinado quanto das formas de proteger a pesquisa que será desenvolvida. Além disso, a atividade permitirá que outras instituições de ensino possam usá-las, além de empresas privadas que, porventura, necessitem criar meios de proteção das suas informações.

O produto da oficina foi de grande relevância para a UFSC e para a Sinova, pois, por meio, tanto da política de confidencialidade quanto da cartilha, as informações estarão mais acessíveis aos interessados e poderão auxiliar quando surgirem situações em que não poderão agir de forma diversa. Além disso, toda essa informação evitará eventuais multas e demandas judiciais por quebra de sigilo de informações.

\subsection{Cultivares e Indicação Geográfica}

Para verificar todas as cultivares registradas e protegidas que tenham a UFSC como titular ou cotitular, após consulta ao sítio eletrônico CultivarWeb do MAPA na internet, foram encontrados oito registros nacionais de cultivares e quatro cultivares protegidas. Esses dados foram tabulados em um relatório, que traz o desenvolvimento das parcerias institucionais e a caracterização de cada cultivar registrada e protegida e, posteriormente, foi disponibilizado para conhecimento e controle da Sinova.

Para levantar os processos de indicações geográficas catarinenses (IP e DO), após pesquisa no sítio eletrônico do INPI, foram encontradas uma IP e uma DO registradas e duas DO em andamento. Com relação aos processos de IG com potencial para demandar parceria com a UFSC no futuro, foram encontrados 27 IGs potenciais e 12 que estão sendo desenvolvidos, com base no banco de dados da Epagri e Sebrae. Esses dados foram tabulados em relatório detalhado e disponibilizado para conhecimento da Sinova.

Após consultar a legislação e pesquisar artigos científicos relacionados aos temas, foram elaborados três folders informativos sobre registro nacional de cultivares, proteção de cultivares 
e indicação geográfica, constando o fluxograma do processo, destacando-se o fluxo processual, o que pode e o que não pode ser protegido e a importância da proteção das proteções. A construção dos folders teve o apoio de um estagiário de design gráfico da Sinova.

Os produtos da oficina foram um relatório com as cultivares pertencentes à UFSC, um relatório com as indicações geográficas catarinenses concedidas, em andamento e que possuem potencial para processos futuros, além de três folders sobre indicação geográfica, proteção de cultivar e Registro Nacional de Cultivares (RNC).

Este trabalho é muito importante, pois permitirá a ampla divulgação desses temas na UFSC, além de contribuir para celebração de projetos futuros da UFSC com outros parceiros, bem como possibilitar o acompanhamento dos processos referentes à Sinova.

\subsection{Política de Inovação}

Após o estudo sobre a legislação que trata de Política de Inovação, identificou-se 31 (trinta e uma) legislações que guardavam relação com o tema (Tabela 3).

Tabela 3 - Legislações consultadas e relacionadas com a Política de Inovação

\begin{tabular}{|c|c|c|c|}
\hline LEIS & DeCREtos & RESOLUÇÕES & Portarias \\
\hline Lei n. 8.958/1994 & $\begin{array}{l}\text { Decreto n. } \\
7.423 / 2010\end{array}$ & 17 Resoluções da UFSC & 5 Portarias da UFSC \\
\hline Lei n. 9.279/1996 & $\begin{array}{l}\text { Decreto n. } \\
9.283 / 2018\end{array}$ & & \\
\hline \multicolumn{4}{|l|}{ Lei n. 9.456/1997 } \\
\hline \multicolumn{4}{|l|}{ Lei n. 10.973/2004 } \\
\hline \multicolumn{4}{|l|}{ Lei n. 13.019/2014 } \\
\hline \multicolumn{4}{|l|}{ Lei n. 13.123/2015 } \\
\hline Lei n. 13.243/2016 & & & \\
\hline
\end{tabular}

Fonte: Elaborada pelos autores deste artigo (2019)

Esses documentos, somados às Políticas de Inovação das instituições consultadas, foram utilizados para estruturar a minuta da Política de Inovação da UFSC.

Os principais pontos observados nos procedimentos da UFSC que precisavam de ajustes foram: oficializar e designar as competências na UFSC; criar mecanismos de regulamentação para afastamento de servidores; promover política de confidencialidade; gerar transferência de tecnologia, participação na exploração e royalties; promover programa de gestão de patentes; revogar a Resolução n. 014/CUN/2002, que trata da propriedade e a gestão de direitos relativos à Propriedade Intelectual; revisar a Resolução n. 23/CUN/08, que trata do programa de incubação de empresas da UFSC; revisar a Resolução n. 1/2018/CPESQ, que dispõe sobre os Laboratórios Centrais Multiusuários na Universidade Federal de Santa Catarina; e revisar a estrutura da Sinova para traduzir a atual necessidade de novos integrantes para reforçar a equipe.

A versão final da minuta foi colocada à disposição do Comitê de Propriedade Intelectual da UFSC que poderá utilizá-la como ponto inicial dos trabalhos, a fim de estabelecer a definitiva Política de Inovação da UFSC. Essa minuta foi composta dos seguintes capítulos: 
a) Capítulo I - Introdução.

b) Capítulo II - Princípios e Diretrizes - Seção I - Disposições Normativas - Premissas; Seção II - Princípios legais a serem seguidos; e Seção III - Objetivos e diretrizes;

c) Capítulo III - Objetivos e Estratégias.

d) Capítulo IV - Governança.

e) Capítulo V - Designação dos Entes Envolvidos.

f) Capítulo VI - Titularidade e Propriedade - Seção I - Titularidade; Seção I - Propriedade.

g) Capítulo VII - Confidencialidade na Criação Intelectual.

h) Capítulo VIII - Acordos e Parcerias - Seção I - Das criações resultantes de acordos e parcerias; Seção II - Das participações dos criadores nos resultados da exploração da Propriedade Intelectual; Seção III - Do apoio a empresas nascentes de base tecnológica; Seção IV - Da Internacionalização de Parcerias; Seção V - Das Incubadoras de Empresas.

i) Capítulo IX - Do Estímulo ao Inventor Independente.

j) Capítulo X - Da Transferência de Tecnologia.

k) Capítulo XI - Do Orçamento para a Inovação.

l) Capítulo XII - Do Afastamento de Servidores.

m) Capítulo XIII - Implementação e Acompanhamento - Seção I - Dos Responsáveis Legais; Seção II - Disposições Finais e Transitórias.

Este trabalho foi de grande relevância, pois trouxe a lume as necessidades de uma política de inovação atualizada, que englobe as atividades da instituição de uma forma perene em matéria de inovação.

O produto da oficina foi uma minuta da política de inovação que auxiliará a Sinova na assessoria do grupo de trabalho formado na UFSC, para elaboração da política de inovação definitiva para a Universidade Federal de Santa Catarina.

\section{Considerações Finais}

Este trabalho relatou quatro casos referentes à Oficina Profissional de quatro alunos do Profnit, ocorridos no primeiro semestre de 2019, com o intuito de veicular a relevante contribuição desta atividade para a Sinova da UFSC, destacando o ganho bilateral dessa parceria de sucesso.

As Oficinas foram desenvolvidas para atender às demandas específicas da Sinova, assistindo em questões que requeriam soluções de pronta resposta e que, provavelmente, não poderiam ser resolvidas pelo efetivo da Sinova dentro da celeridade em que foram atendidas.

Foram várias áreas contempladas com a realização dessa operação, tendo gerado diversos produtos relacionados com estes temas: mapeamento de patentes, portfólio de tecnologias e levantamento de cultivares, indicação geográfica e folders de divulgação sobre cultivar, indicação geográfica e RNC, além de minutas de Política de Inovação e Política de Confidencialidade.

Acredita-se que o relato dessa experiência de sucesso pode servir de referência para outros Pontos Focais do Profnit, de forma a unir o estágio prático da pós-graduação com a geração de resultados e de produtos de impacto imediato em cada NIT associado aos pontos focais, além 
de inspiração para que iniciativas como essa sejam implementadas e replicadas nas políticas públicas envolvendo mestrados profissionais no Brasil.

\section{Referências}

BRASIL. Lei n. 10.973, de 2 de dezembro de 2004. Dispõe sobre incentivos à inovação e à pesquisa científica e tecnológica no ambiente produtivo e dá outras providências. Diário Oficial [da]

República Federativa do Brasil, Brasília, DF, 2004. Disponível em: http://www.planalto.gov.br/ ccivil_03/_ato2004-2006/2004/lei/110.973.htm. Acesso em: 12 ago. 2019.

CULTIVARWEB. [Base de dados - Internet]. Ministério da Agricultura, Pecuária e Abastecimento (MAPA). 2019. Disponível em: http://sistemas.agricultura.gov.br/snpc/cultivarweb/index.php. Acesso em: 12 ago. 2019.

DII - DERWENT INNOVATION INDEX. [Base de dados - Internet]. Clarivate Analytics. 2019. Disponível em: http://apps-webofknowledge.ez46.periodicos.capes.gov.br/DIIDW_GeneralSearch_input. do?product=DIIDW\&SID=7FUgfr58GRtPgp9laox\&search_mode=GeneralSearch. Acesso em: 12 ago. 2019.

\section{FIESC - FEDERAÇÃO DAS INDÚSTRIAS DO ESTADO DE SANTA CATARINA. Observatório} da Indústria Catarinense. 2019. Disponível em: http://fiesc.com.br/pt-br/observatorio-da-industriacatarinense. Acesso em: 12 ago. 2019.

INPI - INSTITUTO NACIONAL DA PROPRIEDADE INDUSTRIAL. [Base de dados - Internet]. 2019. Disponível em: https://gru.inpi.gov.br/pePI/servlet/LoginController?action=login. Acesso em: 12 ago. 2019.

NYSERDA - NEW YORK STATE ENERGY RESEARCH AND DEVELOPMENT AUTHORITY.

Technology Readiness Level - NYSERDA Portal. 2019. Disponível em: https://portal.nyserda. ny.gov/CORE_Solicitation_Document_Page?documentId=a01t0000000LfjoAAC. Acesso em: 12 ago. 2019.

ORBIT QUESTEL. [Base de dados - Internet]. 2019. Disponível em: https://www.orbit.com/. Acesso em: 12 ago. 2019.

PROFNIT - PROGRAMA DE PÓS-GRADUAÇÃO EM PROPRIEDADE INTELECTUAL E TRANSFERÊNCIA DE TECNOLOGIA PARA A INOVAÇÃO. Apresentação do PROFNIT. 2019a. Disponível em: http://www.profnit.org.br/. Acesso em: 12 ago. 2019.

PROFNIT - PROGRAMA DE PÓS-GRADUAÇÃO EM PROPRIEDADE INTELECTUAL E TRANSFERÊNCIA DE TECNOLOGIA PARA A INOVAÇÃO. Exame Nacional de Acesso 2016. 2016. Disponível em: http://www.profnit.org.br/pt/exames/. Acesso em: 12 ago. 2019.

PROFNIT - PROGRAMA DE PÓS-GRADUAÇÃO EM PROPRIEDADE INTELECTUAL E TRANSFERÊNCIA DE TECNOLOGIA PARA A INOVAÇÃO. Normas Acadêmicas Nacionais. Atualizadas na reunião de 13/junho/19 da Comissão Acadêmica Nacional - CAN. 2019b. Disponível em: http://www.profnit.org.br/pt/normas-academicas-nacionais/. Acesso em: 12 ago. 2019.

PROFNIT - PROGRAMA DE PÓS-GRADUAÇÃO EM PROPRIEDADE INTELECTUAL E TRANSFERÊNCIA DE TECNOLOGIA PARA A INOVAÇÃO. Regimento Nacional. Aprovado em 20 de setembro de 2018 pela Diretoria e Diretório do FORTEC. 2018. Disponível em: http://www. profnit.org.br/pt/regimento-nacional/. Acesso em: 12 ago. 2019. 
SINOVA - SECRETARIA DE INOVAÇÃO DA UFSC. 2019. Disponível em: http://sinova.ufsc.br/. Acesso em: 12 ago. 2019.

\section{Sobre os Autores}

\section{Breno Ricardo de Araújo Leite}

E-mail: guardiao78@gmail.com

Mestrado em Ciências e Tecnologias Espaciais pelo Instituto Tecnológico de Aeronáutica em 2017.

Endereço profissional: Instituto de Estudos Avançados, Trevo Coronel Aviador José Alberto Albano do Amarante, n. 1, Bairro Putim, São José dos Campos, SP. CEP: 12228-001.

\section{Paulo Roberto Lisboa Arruda}

E-mail: lisboa@epagri.sc.gov.br

Especialização em MBA Executivo em Liderança e Gestão Organizacional pela Universidade do Sul de Santa Catarina em 2017.

Endereço profissional: Empresa de Pesquisa Agropecuária e Extensão Rural de Santa Catarina, Departamento Estadual de Extensão Rural e Pesca, Rodovia Admar Gonzaga, n. 1.347, Itacorubi, Florianópolis, SC. CEP: 88034-901.

\section{Danielle Regina da Natividade Ferreira}

E-mail: danielle.adv.sc@gmail.com

Especialização em Direito e Processo do Trabalho e Previdenciário pelo Centro Universitário Estácio Ribeirão Preto em 2017.

Endereço profissional: Sindicato dos Trab. em Saúde e Prev. do Serv. Púb. Federal do Estado de SC, Departamento Jurídico, Rua Ângelo La Porta, Centro, Florianópolis, SC. CEP: 88020-600.

\section{Thiago Domingos Marques}

E-mail: alfabeta19@hotmail.com

Especialização em Direito Administrativo pela Universidade Cândido Mendes em 2016.

Endereço profissional: Reitoria do Instituto Federal Catarinense, Rua das Missões, n. 100, Ponta Aguda, Blumenau, SC. CEP: 89051-000.

\section{Alexandre Moraes Ramos}

E-mail: amrrms@gmail.com

Doutorado em Engenharia de Produção pela Universidade Federal de Santa Catarina em 2000.

Endereço profissional: Universidade Federal de Santa Catarina, Instituto de Pesquisas e Estudos em Administração Universitária, Campus Universitário Trindade, Centro Socioeconômico, Bloco C, $2^{\circ}$ andar, Trindade, Florianópolis, SC. Caixa-postal: 476. CEP 88040-900.

\section{Irineu Afonso Frey}

E-mail: irineu.inova@gmail.com

Doutorado em Engenharia de Produção pela Universidade Federal de Santa Catarina em 2005.

Endereço profissional: Universidade Federal de Santa Catarina, Departamento de Ciências Contábeis, Centro Socioeconômico, Campus Universitário, Trindade, Florianópolis, SC. CEP: 88040-970. 